\title{
Metamemory and metalinguistic development: Correlates of children's intelligence and achievement
}

\author{
JOHN G. BORKOWSKI, ELLEN BOUCHARD RYAN, BETH E. KURTZ, \\ and MARY $K$. REID \\ University of Notre Dame, Notre Dame, Indiana
}

\begin{abstract}
The interrelationships between metamemory and metalinguistic development and their association with verbal intelligence and academic achievements were examined for 80 children in first and third grades. At both grade levels, metamemory correlated significantly with metalinguistic development. The moderate strength of the association was to be expected from a contrast of the two distinct theoretical constructs that are only indirectly linked within the more general concept of metacognition. For children of both ages, relationships between metamemory and metalinguistic level and those between a combined index of metacognition and achievement did not remain significant when the effects due to verbal intelligence were partialed out. The association between the combined index and a metareading assessment was significant for first-grade children, independent of verbal intelligence.
\end{abstract}

Metacognition refers to self-knowledge about cognitive processes and structures (Flavell, 1979). Two important components of metacognition are metamemory (knowledge about memory processes) and metalinguistic awareness (knowledge about language features and functions). Although each component has its unique theoretical importance in theories of memory (Borkowski, in press) and language (Downing, 1979; Ryan \& Ledger, in press), their conceptual and empirical links are tenuous. Yet, each is a specialized form of knowledge that may be important in explaining how children learn to function in a cognitively sophisticated manner in their environments. This article outlines empirical contact points between metamemory and metalinguistic development and their association with general intelligence and achievement.

Kurtz, Reid, Borkowski, and Cavanaugh (1982) developed a six-item metamemory battery, assessed its reliability, and demonstrated its validity by showing its relationship with the transfer of an acquired elaborative strategy. Similarly, Ryan and Ledger (1982) showed that metalinguistic knowledge of phonological and syntactic features and of the functions of reading correlate with early reading and sentence-memory performance. In the present study, 80 first- and thirdgrade children were given metamemory and metalinguistic batteries and the WISC-R Vocabulary subtest, a

This research was supported by the National Institute of Education (G81-0134). E. B. Ryan is currently in the Department of Psychiatry, McMaster University. Reprint requests should be sent to John G. Borkowski, Department of Psychology, University of Notre Dame, Notre Dame, Indiana 46556. word recognition test of reading, and a standardized achievement test.

\section{METHOD}

\section{Subjects}

A total of 80 children from two urban parochial schools participated. The sample consisted of 39 first-graders $(\mathrm{CA}=$ 6.7 years) and 41 third-graders $(\mathrm{CA}=8.6$ years); 43 of the children were male and 37 were female. Approximately $98 \%$ of the sample was Caucasian.

\section{Materials}

The metamemory battery comprised six subtests. Four subtests were selected from the metamemory battery designed by Kreutzer, Leonard, and Flavell (1975): Story List, Preparation Object, Retrieval Event, and Rote Paraphrase. These subtests have been shown to be the most valid and sensitive indicators of metamemory in the Kreutzer et al. (1975) questionnaire for children between 6 and 9 years of age (Cavanaugh \& Borkowski, 1980). Two other subtests-Memory Monitoring and Interest Categories-differed from the first four in terms of assessing procedural aspects of memory. In short, the first four subtests consisted of the assessment of verbalized, declarative knowledge regarding the actions of a hypothetical child, whereas the other two subtests encouraged the child to engage actively in tasks requiring metamemorial judgments. Details of the administration and scoring of these subtests can be found in Kurtz et al. (1982). For purposes of the present research, raw scores for each subtest were transformed into standard (i.e., "z") scores and summed across subtests for each child. Thus, a composite metamemory index giving equal weight to each subtest was formed.

The metalinguistic battery included three subtasks: Sentence Judgment, Auditory Blending, and Word Segmentation. Sentence Judgment measured the ability to distinguish between grammatical and ungrammatical sentences presented orally. Following practice exercises, children heard two taped versions of each of 18 sentences and selected the well-formed version 
from each pair. Auditory Blending, a subtest of the Illinois Test of Psycholinguistic Abilities, measured the ability to combine separate phonemes into words and pseudowords. Word Segmentation assessed the children's ability to visually distinguish words with and without sentence contexts (Klein, Klein, \& Bertino, 1974). Six word strings (three grammatically correct sentences and three random word combinations) were presented with no spaces printed between words. The children were instructed to draw vertical lines between the words, which were selected at an early first-grade readability level.

Other measures included the WISC-R Vocabulary subtest, the Iowa Test of Basic Skills (achievement), and Slosson Oral Reading Test, a metareading question, and teacher ratings of metamemory. The metareading question assessed knowledge of the meaning function of reading (i.e., "What is the main goal of reading?"). Ambiguous or partial answers were expanded with probes; each child's best answer was classified as meaning-based or not. Several studies (Downing, 1979; Myers \& Paris, 1978; Paris \& Myers, 1981) have demonstrated that functional knowledge about reading improves with age from kindergarten through the middle grades and that poor readers typically do not verbalize the "extraction-of-meaning" goal of reading. Teacher ratings were obtained in an after-school session in which the experimenter briefly discussed the concept of metamemory. Each teacher was then given a class list with a one-sentence definition of metamemory (as the child's knowledge about his or her own memory processes) and asked to rank each student as having high, medium, or low metamemory skills.

\section{Procedure}

The children were tested individually in an area near their classroom. Before beginning the metamemory assessment, the children were told that the experimenters were trying to learn about how memory works in children. If children misunderstood or failed to respond to questions in the battery, the questions were rephrased and asked again. Probes were used to encourage shy children to respond and to clarify ambiguous answers. The metamemory battery was given early in the academic year in a single .5-h session. The Sentence Judgment, Auditory Blending, Metareading, WISC-R Vocabulary, and Slosson Reading tasks were given in two sessions in early spring, approximately 5 months after the metamemory testing.

Word Segmentation was administered in the children's classrooms, with all children at a particular grade level taking the test simultaneously. The Iowa Test of Basic Skills was administered by teachers; however, 19 first-graders did not receive this test. The experimenters met with teachers to obtain their ratings of the children's metamemory ability; this meeting occurred late in the academic year, 5 to 6 months after the children had been given the metamemory battery.

\section{RESULTS}

\section{Internal Consistency of Metamemory}

Raw scores for each of the metamemory subtests were converted to standard $\mathrm{z}$ scores. Tables 1 and 2 show correlation matrices reflecting the internal consistency of individual subtests with one another and with the sum of all other subtests for the first- and the third-graders. All subtests for the first-graders correlated significantly with the sum of the other five subtests, with correlations ranging from $\mathrm{r}=.38$ for Memory Monitoring to $r=.60$ for Interest Categories. Nine of the 15 correlations beween pairs of subtests were significant, and the average of the 15 correlations was .32. Metamemory for the third-graders was much less consistent than metamemory for the younger children. Of the
Table 1

Pearson Correlations of Metamemory Subtests for First-Grade Children

\begin{tabular}{lclllll}
\hline & PO & RE & RP & MM & IC & PS \\
\hline Story List & .34 & .16 & $.43^{* *}$ & .15 & .26 & $.39 *$ \\
Preparation: Object & & $.32 *$ & $.48^{* *}$ & .16 & $.40^{* *}$ & $.54 \dagger$ \\
Retrieval: Event & & & .24 & $.42 * *$ & .14 & $.49 \dagger$ \\
Rote-Paraphrase & & & & .14 & $.33 \dagger$ & $.50 \dagger$ \\
Memory Monitoring & & & & & $.44 * *$ & $.38^{*}$ \\
Interest Categories & & & & & & $.60 \dagger$ \\
\hline
\end{tabular}

Note $-P O=$ preparation $:$ object, $R E=$ retrieval: event, $R P=$ rote paraphrase, $M M=$ memory monitoring, $I C=$ interest categories, and $P S=$ partial sum. $\quad{ }^{*} p<.05 . \quad{ }^{* *} p<.01 . \quad \dagger p<.001$.

Table 2

Pearson Correlations of Metamemory Subtests for Third-Grade Children

\begin{tabular}{llllrrr}
\hline & PO & RE & RP & MM & IC & PS \\
\hline Story List & -.01 & .00 & $.37^{*}$ & .00 & .07 & .16 \\
Preparation: Object & & $.32 *$ & $.32^{*}$ & -.02 & -.01 & .23 \\
Retrieval: Event & & & -.06 & -.05 & .02 & .08 \\
Rote-Paraphrase & & & & .04 & .05 & .29 \\
Memory Monitoring & & & & & $.31^{*}$ & .10 \\
Interest Categories & & & & & & .17 \\
\hline
\end{tabular}

Note $-P O=$ preparation $:$ object,$R E=$ retrieval $:$ event,$R P=$ rote paraphrase, $M M=$ memory monitoring, $I C=$ interest categories, and $P S=$ partial sum. $\quad{ }^{*} p<.05$.

15 correlations between pairs of subtests, only 4 were significant; the mean of the 15 was only .09. Although all correlations of individual subtests with the sum of the other five were positive, none of the 6 was significant.

In spite of age-related differences in metamemory, a consistent developmental pattern among subtests emerged. Individual correlations that were highest within the first grade tended to be highest within the third grade. Also, the four correlations that were significant for the third grade were significant, but higher, for the first grade.

\section{Metalinguistic Development}

Transformed according to the same procedures as in the metamemory battery, the data from the metalinguistic tasks were converted to $\mathrm{z}$ scores for purposes of combining scores. Of the three tasks, Word Segmentation correlated consistently with the other subtests; this pattern of consistency was similar for the first and third grades. Table 3 shows correlations between individual tasks, between each task and the sum of the remaining two, and with the composite metamemory score. For both grades, the three metalinguistic tasks correlated consistently with the sum score.

A significant relationship between metamemory and metalinguistic knowledge was found at each grade level. That is, correlations between the two composite scores were significant for both grades $(r=.37, p<.05$, in both cases), whereas half of the correlations between metamemory and individual metalinguistic tasks were 
Table 3

Pearson Correlations of Metalinguistic Tasks and Metamemory for Children in First and Third Grades

\begin{tabular}{lllll}
\hline AB & WS & PS-MI & Mm
\end{tabular}

Sentence Judgments

Auditory Blending

Word Segmentation

Partial Sum-Metalinguistic

First Grade

$\begin{array}{llll}.26 & .60 \dagger & .49 * * & .33^{*} \\ & .44^{* *} & .38^{*} & .22 \\ & & .66 \dagger & .32 * \\ & & & .37 *\end{array}$

Third Grade

\begin{tabular}{lllll} 
Sentence Judgments & $.32 *$ & $.31^{*}$ & $.38^{*}$ & $.36^{*}$ \\
Auditory Blending & & $.38^{*}$ & $.43^{* *}$ & .29 \\
Word Segmentation & & & $.42^{* *}$ & .20 \\
Partial Sum-Metalinguistic & & & & $.37 *$ \\
\hline
\end{tabular}

Note $-A B=$ auditory blending, $W S=$ word segmentation, $P S-$ $M l=$ partial sum-metalinguistic, $M m=$ metamemory .

${ }^{*} p<.05 . \quad{ }^{* *} p<.01 . \quad \quad t p<.001$.

significant. These moderate overall metamemorymetalinguistic relationships did not remain significant when WISC-R Vocabulary scores were partialed out.

\section{Correlates of Metacognition}

An index of metacognition, including metamemory and metalinguistic subtasks, was found to correlate significantly with intelligence for first-graders $(r=.64$, $\mathrm{p}<.001)$ and third-graders $(\mathrm{r}=.54, \mathrm{p}<.001)$. In addition, the metacognition index correlated significantly with achievement, as measured by the Iowa Basic, for first-graders $(\mathrm{r}=.61, \mathrm{p}<.01)$ and third-graders $(\mathrm{r}=.53$, $p<.01)$. These correlations did not remain significant when WISC-R Vocabulary scores were partialed out $(\mathrm{p}<.10)$. For Slosson Reading scores, the metacognitive index correlated significantly for first-graders $(\mathrm{r}=.43, \mathrm{p}<.05)$ and remained significant when the variability due to WISC scores was removed.

Point-biserial correlations between the Metareading and the composite metacognition scores were significant only for first-graders $(r=.43, p<.05)$. This association remained significant when WISC scores were partialed out.

Teacher ratings of metamemory were analyzed with point-biserial correlations, with metamemory rating ( $1=$ low and $2=$ high) being used as the dichotomous variable; this classification was possible because there were few middle judgments. The point-biserial correlation with the metamemory score was calculated for data collapsed across grades for available subjects, and yielded a significant correlation $(\mathrm{r}=.37, \mathrm{p}<.05)$. This correlation suggests that teachers can recognize, in a general way, those children who possess good and poor information about their memory processes, although this judgment is often confounded by other aspects of intelligent behavior. That is, the point-biserial correlation between teacher ratings about memory and children's actual knowledge became nonsignificant when the WISC scores were partialed out.

\section{DISCUSSION}

This study broadens the scope of metamemory by determining its overlap with metalinguistic development, metareading, achievement, and intelligence. When raw scores for the metamemory and metalinguistic subtasks were converted to standard scores and pooled, the two tests were found to correlate significantly, accounting for approximately $14 \%$ of the common variance at both grade levels. Metalinguistic ability, as measured by our selection of subtasks, showed only a moderate relationship with metamemory. This is to be expected from a contrast of two distinct theoretical constructs that are only indirectly linked by the more general concept of metacognition. The dependency of this association upon verbal intelligence was not anticipated. In contrast, the relationship between the combined metamemory-metalinguistic index and the Metareading dichotomy for first-grade children was independent of the intelligence measure and indicates additional cross-domain generality of the metacognition concept.

Age-related changes were found in the internal consistency of both metacognitive assessments, with greater consistency for first-graders than for third-graders. This trend was especially evident for metamemory. On the one hand, apparent shifts in consistency may have been caused by internal features of the batteries. For example, a ceiling effect appeared to be operating for third-graders on the Story List subtest. On the other hand, it is likely that age-related changes in the consistency of metamemory do, in fact, exist. With increasing age of subjects, metamemorial knowledge becomes more specialized and diversified and contributes to greater variance of individual performance across subtests and to less consistency within children of the same age. This accounts for the relatively low test-retest correlation $(r=.63)$ found when metamemory information on two occasions separated by a 6-week interval is compared (Kurtz et al., 1982).

The potential role of metacognition in academic achievement has considerable applied, as well as theoretical, significance (Brown, Bransford, Ferrara, \& Campione, 1983). To progress in our understanding of this interplay, it is essential to measure key aspects of metacognition and to begin to relate these to indices of school achievement. Strong relationships were observed here between our metacognition index and verbal intelligence and between that index and achievement. In the future, research should clarify theoretical distinctions and points of overlap between the different domains of metacognition. As argued by Bialystok and Ryan (in press), metacognitive tasks (e.g., from the memory, language, reading, and attention domains) differ in their demands along two basic dimensions: cognitive control (selection and coordination of information and strategies) and analyzed knowledge (degree of structure in the knowledge accessible to the learner). Hence, one would expect stronger relationships to be found between metamemory and metalinguistic development if sets of subtasks with similar requirements on these two dimensions were designed.

Finally, the likely consequence of the 6-month gap between the metamemory testing and the administration of the other measures needs to be considered. On the basis of this asynchrony of testing, the relationships of metamemory with metalinguistic and achievement measures obtained in this study can be viewed as underestimations of the true relationships existing at any given point. We suggest that, in the future, work on metacognition theory will need to attend more to the developmental aspects of its components, such as metamemory and metalinguistics, especially in terms of their unique environmental antecedents and applied influence.

\section{REFERENCES}

Bialystok, E., \& Ryan, E. B. Metacognitive framework for the development of first and second language skills. In D. L. Forrest- 
Pressley, G. E. Mackinnon, \& T. G. Waller (Eds.), Metacognition, cognition, and human performance. New York: Academic Press, in press.

Borkowski, J. G. Signs of intelligence: Strategy generalization and metacognition. In S. Yussen (Ed.), The development of reflection in children. New York: Academic Press, in press.

Brown, A. L., Bransford, J. D., Ferrara, R. A., \& Campione, J. C. Learning, remembering, and understanding. In J. H. Flavell \& E. M. Markman (Eds.), Carmichael's manual of child psychology (Vol. 1). New York: Wiley, 1983.

Cavanaugh, J. C., \& Borkowski, J. G. Searching for metamemory-memory connections. Developmental Psychology, $1980,16,441-453$.

Downing, J. Readng and reasoning. New York: Springer-Verlag, 1979.

Flavell, J.H. Metacognition and cognitive monitoring: A new area of cognitive-developmental inquiry. American Psychologist, 1979, 34, 906-911.

Klein, H. A., KLein, G. A., \& Bertino, M. Utilization of context for word identification decisions in children. Journal of Experimental Child Psychology, 1974, 17, 79-86.

Kreutzer, M. A., Leonard, C., \& Flavell, J. H. An interview study of children's knowledge about memory. Monographs of the Society for Research in Child Development, 1975, 40(1, Serial No. 159).

Kurtz, B. E., Reid, M. K., Borkowski, J. G., \& Cavanaugh, J. C. On the reliability and validity of children's metamemory. Bulletin of the Psychonomic Society, 1982, 19, 137-140.

Myers, M., \& Paris, S. G. Children's metacognitive knowledge about reading. Journal of Educational Psychology, 1978, 70, 680-690.

Paris, S. G., \& Myers, M. Comprehension monitoring, memory and study strategies of good and poor readers. Journal of Reading Behavior, 1981, 13, 5-22.

Ryan, E. B., \& Ledger, G. W. Assessing sentence processing skills in prereaders. In B. A. Hutson (Ed.), Advances in reading/language research (Vol. 1). Greenwood, Conn: JAI Press, 1982.

RyAN, E. B., \& LEDGE R, G. W. Learning to attend to sentence structure: Links between metalinguistic development and beginning reading. In $J$. Downing \& $R$. Valtin (Eds.), Language awareness and learning to read. New York: Springer-Verlag, in press.

(Manuscript received for publication June 24, 1983.) 